\title{
A LARGE MALE COMPETITIVE ADVANTAGE IN A LEKKING FLY, HERMETIA COMSTOCKI WILLISTON (DIPTERA: STRATIOMYIDAE)*
}

\author{
By John Alcock \\ Department of Zoology, \\ Arizona State University, Tempe, AZ 85287-1501
}

\section{INTRODUCTION}

This paper describes the mating system of Hermetia comstocki Williston, a stratiomyid fly that, like many other members of the family (Waldbauer, 1984), appears to be a Batesian mimic, in this case of Polistes paper wasps (James, 1935). Little is known about this species other than it occurs in Arizona, New Mexico and Texas (Cole, 1970). In general, not much information exists on the mating behavior of stratiomyids. Females of one species, Inopus rubriceps, which is a pest of sugarcane, have been reported to fly to the lower leaves of the hostplant shortly after emerging; males rush to surround the female although presumably only one male copulates with the female, after which she leaves to oviposit and die (Hitchcock, 1976). In contrast to the scramble competition system exhibited by $I$. rubriceps, I shall document that $H$. comstocki engages in territorial defense of landmark plants to which females travel to secure a mate. Furthermore, I present data on the role body size plays in the competition among males for possession of mating territories.

\section{Methods}

This study took place over two periods, from 26 May to 6 June 1990 and from 27 July to 4 August 1990, in the Chiricahua Mountains, Coronado National Forest, in southeastern Arizona. The primary study site was an east facing slope at an elevation of approximately 5500 feet in open oak-juniper woodland. The flies were also watched briefly in desert scrub with scattered creosote and acacia at about 5000 feet elevation at a location $12 \mathrm{~km} \mathrm{~N}$ on the Foothills Road from Portal to San Simon, AZ.

*Manuscript received by the editor September 20, 1990. 
The flies were found perched on plants, primarily Agave palmeri, which in the primary study site grew along a small gully in the woodland. Ten potential perch sites that occurred in a hundred $\mathrm{m}$ stretch of the gully were selected for censusing. Over 8 days in the first study period, 35 censuses at intervals of at least 30 min between counts yielded data on the relative popularity of the perching locations as well as on the site tenacity of marked individuals. Repeated censuses were also conducted during the second study period, but at intervals of 15 min over 4 days for a total of 76 censuses.

To create identifiable males, individuals were captured in a net and then marked with dots of Liquid Paper Typewriting Correction Fluid on the thorax, abdomen or wings. Released flies almost invariably returned to their perches, facilitating observation of known individuals.

Between 27 May and 3 June and on 28 and 29 July within the hours of 0900 to 1500 M.S.T., 15 marked males were selected for continuous observation of between 30 and $120 \mathrm{~min}(\overline{\mathrm{x}}=50 \pm 27.0$ $\mathrm{min}$ ) in order to document the frequency with which males patrolled their perches and interacted with conspecifics.

In order to determine whether males were territorial and whether body size influenced the outcome of contests for control of perch sites, the identity of the male that returned to the perching site after an interaction with another male was recorded. Whenever possible, the relative size of the two males was noted prior to a clash (often the two males would share the same agave briefly) and the eventual "winner" subsequently noted after one male only returned following an interaction.

In addition, some males were captured at agaves away from the study site and transferred to occupied agaves elsewhere. Because of the remarkable "tameness" of these flies, they would usually walk onto or fly into the agave when removed from the net by hand. Prior to the release, the relative sizes of the two males were noted and then the outcome of the interaction between them recorded.

In addition, I noted the results of any male-male (and malefemale) encounters at times outside the continuous observation periods. The high degree of sexual dimorphism in this species facilitated identification of the sexes (females are usually much larger than males and are differently colored as well). 


\section{RESUlts}

Selection of perch sites

The flies that perched on agaves were usually males. During the study 42 perch-occupying males were netted and marked at one or another of the ten perch plants on the study site. Not all males were captured and marked, so that the total number of males present over the course of the study was considerably greater than 42 .

All sightings of females were recorded and on the assumption that no female appeared more than once at the site, the total number of female visitors was 20 . Furthermore, females stayed only for a few minutes at the site as a rule, whereas males often remained for much longer periods. The operational sex ratio was clearly highly skewed toward males.

Some plants were far more likely to be occupied by a male than others. During the first study period, males were found at all but one of the ten sites, with two plants (\#4 and \#5) accounting for $50 \%$ of all records of occupied sites. During the second study period, again nine of ten plants were occupied by a male during at least one census. Three plants (\#4, \#8 and \#5) accounted for $71 \%$ of all records of occupied sites. There was a strong correlation in the rankings of the 10 sites (as measured by frequency of occupation during censuses) by the different populations of males present in early June versus early August (Spearman's rank correlation coefficient, $r=$ $0.82, \mathrm{P}<0.01)$.

Frequently occupied sites did not possess obvious similarities. At the primary study area, the preferred perches (\#4, \#5, and \#8) were a large living agave with green leaves, a very small living yucca immediately adjacent to a small dead agave with brown leaves, and a very large agave with some living and some dead leaves. At the secondary study site, in which there were great numbers of living and dead agaves scattered across the open landscape, males showed a preference for agaves that had died and turned brown. In a sample of 100 agaves with diameters in excess of one meter at this location, males were present on just 4 of 60 living agaves and on 11 of 40 dead agaves $($ Chi square $=6.62, \mathrm{P}=0.01$ ).

Behavior at perch sites

Males first appeared at the perch plants between 0900 and 1000 
M.S.T. and the last males left some time in the mid- to late afternoon with a few seen as late as 1600 to 1700 . While present, they generally rested on the upper surface of the leaves of the selected plant, facing down toward the center of the plant (Fig. 1). The males were remarkably inactive, only rarely shifting position in the plant (65 records in $750 \mathrm{~min}$ of continuous observation or 1 brief flight among the leaves of their perch site per $11.5 \mathrm{~min}$ of residency). Interactions with conspecific males were even rarer (10 in $750 \mathrm{~min}$ or 1 per $75 \mathrm{~min}$ ).

Encounters between males followed a standard pattern. When the male occupying the plant detected a newcomer, generally as the intruder flew into the plant or patrolled among its leaves, he quickly flew up to meet the new male. The two then either flew off in a horizontal chase or more commonly, they ascended upwards flying in close proximity to each other. While ascending 5 to $15 \mathrm{~m}$, the males seemed to face one another, before one turned to fly off with the other racing after him. Although both males might then return to perch on the plant, invariably the flight of one would trigger another chase or ascending flight. Sooner or later, only one male returned to the perch plant. The same plant did not hold more than

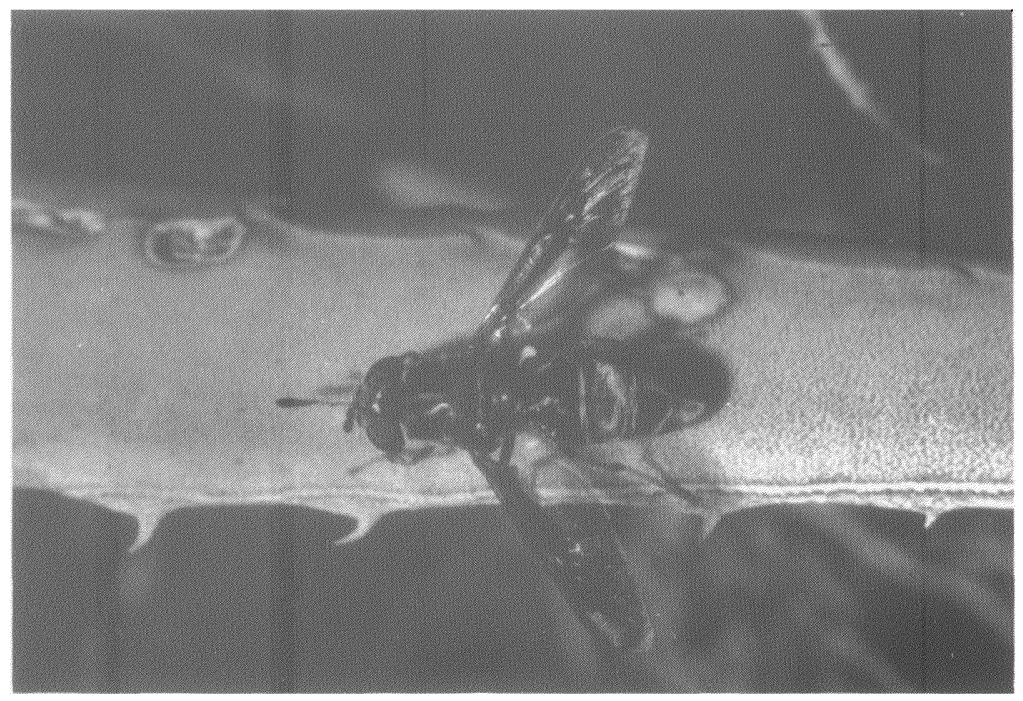

Fig. 1. A male of Hermetia comstocki perched on a leaf of Agave palmeri facing down toward the base of the plant. 
one perching male for more than half an hour in any case, and the vast majority of interactions led to the departure of one male within a couple of minutes.

Body size and territorial success

Males of $H$. comstocki vary greatly in body size with some males easily three times as long and much heavier still than the smallest members of the population. The influence of body size appears dominant in territorial clashes for control of perch sites. When a newcomer was smaller than the current occupant of an agave or yucca it invariably was repelled by the resident. However, when a rival was larger than the current resident, it had an excellent chance of taking over the territory (Table 1).

Combining natural observations and experimental results, the resident male won 33 of 53 clashes $(P=0.05$, sign test $)$ whereas the larger male won 38 of 43 contests (excluding 10 cases in which the two males were of apparently equal size; $\mathrm{P}<0.001$, sign test).

Site tenacity

Marked males quickly returned to their territories after release, and some remained on station for up to $6 \mathrm{hr}$ with many staying at the study site for more than $90 \mathrm{~min}(\mathrm{~N}=20$ records). However, individuals commonly moved from one plant to another during one day's tenure at the study area ( $\mathrm{N}=29$ records of such moves). As a result of voluntary switches and active takeovers, many agaves had more than one male owner in the course of a single day $(\mathrm{N}=17$ records of from 2 to 5 males occupying the same agave during four days of repeated censuses in the period from 31 July to 4 August).

Table 1. The significance of body size in determining winners in territorial contests between males of Hermetia comstocki in natural (nonmanipulated) encounters and experimental encounters, in which a captured male was transferred to and released at an occupied site.

\begin{tabular}{lccc}
\hline Natural Encounters- & & & \\
Intruder is & smaller & . . same size as & . .larger than resident \\
Intruder wins & 1 & 2 & 8 \\
Intruder loses & 18 & 5 & 1 \\
\multicolumn{5}{l}{ Experimental Encounters- } & & \\
Transferred male is $\quad$ smaller & . .same size as & ..larger than resident \\
Transferred male wins & 0 & 2 & 7 \\
Transferred male loses & 5 & 1 & 3 \\
\hline
\end{tabular}


The data are inconsistent with respect to the tendency of males to return to the study site on more than one day. During the first period of study, only 10 of 29 males marked between 26 May and 5 June were seen again at the study site. During the second period, however, 11 of 13 males marked between 28 July and 4 August returned on another day for at least one additional bout of territoriality at one of the ten agaves. The difference between the two periods in the probability of males returning for two or more days of territorial defense is significant (Chi square $=6.08, \mathrm{P}<0.02$ ).

There are many possible explanations for the apparent differences in the site tenacity of males early and later in the flight season. I have evidence on only one hypothesis, which is that mortality rates differed in the two periods. In late May/early June, large Efferia robberflies were numerous and I observed four cases in which they captured a male $H$. comstocki (Fig. 2), either when the stratiomyid made a perch-shifting flight about his agave $(\mathrm{N}=3)$ or during an ascending flight interaction between two males $(\mathrm{N}=1)$.

In late July/early August, Efferia robberflies were highly uncommon and I saw only one case in which a male stratiomyid was taken by the predatory fly.

The function of territoriality

Males apparently defended perching plants because these plants were sometimes visited by receptive females. Of the 20 females seen on the study area, 12 mated with a territory owner. Matings occurred between 0944 and 1425 during encounters that took the following form. A female flew near a perched male, either while approaching a territory or after flying up from a perch on the territory. The males approached the flying female, captured her in the air, and initiated copulation while mounted on her back. The pair soon landed, usually on the territorial plant (Fig. 3) where copulation in a back-to-back position was completed after a mean of $14.3 \pm 4.7 \min (\mathrm{N}=10)$.

One male secured two copulations within 30 min, demonstrating the capacity for polygyny in the species.

The 12 receptive females all were observed at the three perch sites that males most favored (\#4, \#5, \#8). With one exception, they mated with the first male to grasp them. The one exception occurred at a plant that happened to have two males present. Both males attempted to copulate with the female simultaneously on two occa- 


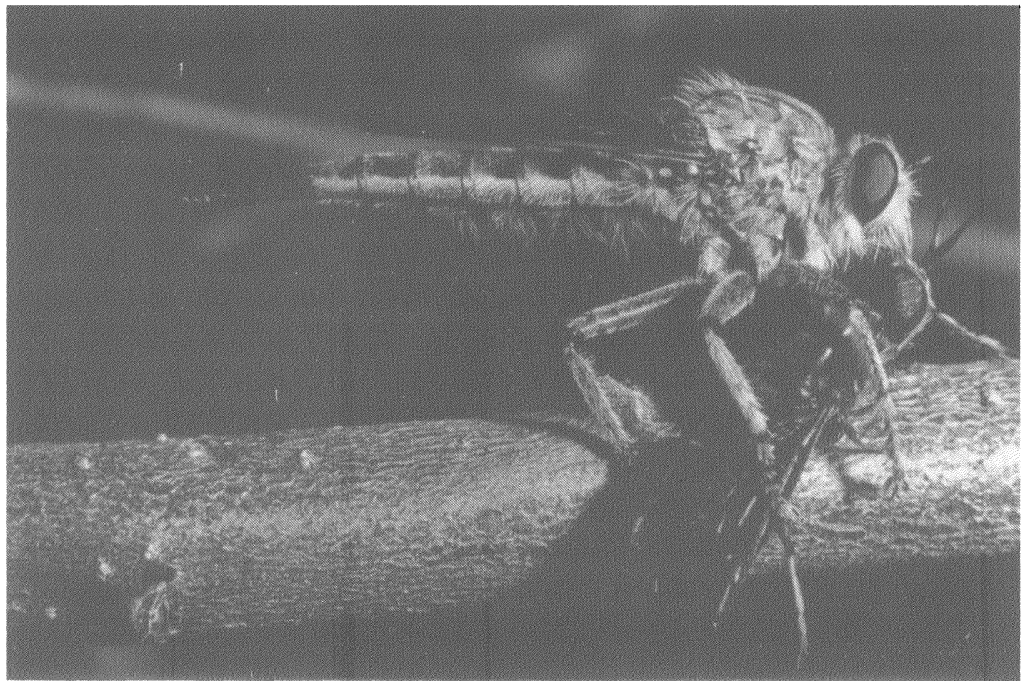

Fig. 2. A robberfly (Efferia sp.) that has captured and killed a male of Hermetia comstocki.

sions but without success. When moved by an observer to another occupied plant, the female mated on the first attempt with the single male present there.

Of the eight apparently nonreceptive females, five flew directly away from the agaves on which they were perched (unlike the receptive females, which circled around the plants they visited). Although pursued for some distance by males, these five females did not copulate but disappeared from sight.

Three of the eight nonreceptive females did remain for some time at the dead agaves that they visited. These individuals disappeared among the loose leaves of the plants and two were not seen exiting. The activities of these two within the plant could not be observed. Another female stayed at the plant for several minutes, closely inspecting a patch of decayed matter in the center of the plant before she left without ovipositing.

On several agaves off the study site females were seen pressing their mouthparts forcefully on the surface of green leaves in a manner that suggested they were feeding there. "Feeding" bouts were brief, lasting only a few minutes. 


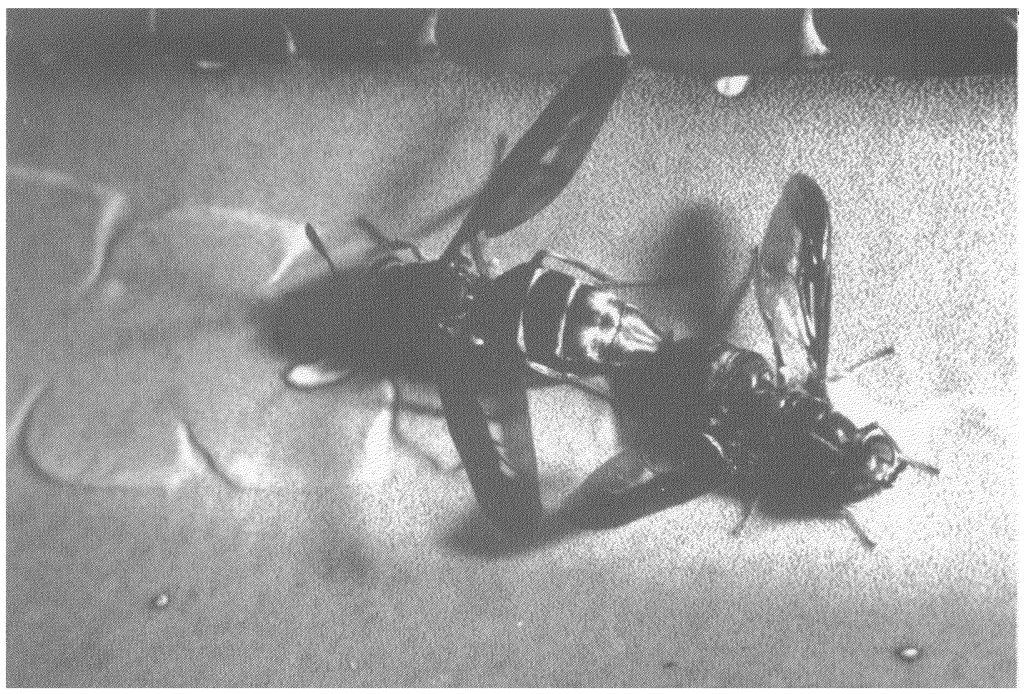

Fig. 3. A pair of Hermetia comstocki (the smaller male on the right) copulating on a leaf in the agave territory of the male.

No female that copulated on the study site stayed at the mating perch for more than a few minutes before flying off in a straight line without having oviposited or fed at the plant.

\section{Discussion}

Resource-defense or lek polygyny?

If we use the mating system classification of Emlen and Oring (1977), males of $H$. comstocki might be placed either in the resource-defense or male dominance (lek) polygyny categories. On the one hand, there appears to be some chance that the plants occupied by males and visited by females provided resources for some females (perhaps oviposition sites or food). However, the possibility seems slight for the following reasons. Almost all recentlymated females quickly abandoned the agaves and yuccas held by their territorial mates. Moreover, long dead, dying, and healthy living agaves were all accepted by territorial males, and it seems unlikely that all could have provided the same useful resource to females.

Therefore, I conclude that males are probably engaged in lek polygyny in which they defend certain plants primarily because 
these plants offer convenient landmarks, but no useful resources, for mate-searching females. Agaves offer distinctive visual forms in oak-juniper woodland and elsewhere. They appear to have become a key rendezvous site in a mating convention shared by males and females of $H$. comstocki.

The behavior of males of $H$. comstocki is highly similar to that of other insects with nonresource-based (landmark-based) mating systems. The group is characterized by the defense of entire plants or other relatively large territories by single males that use rapid ascending flight contests to determine ownership of sites (Alcock, 1987).

The stratiomyid's behavior appears especially convergent with that of the unrelated mydid fly, Mydas ventralis, whose males defend prominent hilltops (Alcock, 1990). Males of both species typically spend several hours at locations with suitable perch sites but may move between different landmarks in the course of one day. Females fly to the landmarks and make themselves conspicuous through circling flights that attract males, which copulate with them in the air before settling on nearby vegetation. Mate choice by females of both species appears limited because they generally accept the first male able to grasp them in flight.

Factors influencing male territorial tactics

If we accept that males are attempting to control landmark territories, several questions follow including, (1) how do males select which plants to defend and (2) how do they resolve competition among themselves for possession of agave territories?

Males have clear territorial preferences. Many agaves are rarely, if ever, defended by males while others may be occupied only occasionally, and still others held almost continuously from 1000 to 1500. The preferred agaves had no obvious (to a human observer) features that distinguished them from less favored plants. Nevertheless, two populations of males separated in time by two months ranked the set of ten in the primary study site very similarly, suggesting that there must be stable key cues which enable individuals to identify landmarks worth defending. Males of a number of other landmark-defending insects also tend to rank potential territories consistently over the long term, even from year to year (e.g. Alcock, 1983; O’Neill, 1983; Toft, 1989).

If male territorial preferences have evolved via sexual selection, 
one would predict that favored sites should be associated with disproportionate access to females, a point established for lekking insects by Lederhouse (1982) and Shelly (1987). Although sample sizes are small, the results of this study support this prediction, in that receptive females $(\mathrm{N}=5)$ appeared exclusively at the three agaves most popular with males in the period from 31 July to 4 August. Then the ten agaves were censused equally every $15 \mathrm{~min}$, making it unlikely that any copulation at the ten censused agaves would go undetected (given a mean copulation time of more than 14 $\min$ ).

Resolution of territorial conflicts

Male-male encounters were infrequent and were resolved quickly (within a few min) in almost all cases. As is true for many landmark defending insects (Alcock, 1987), the interactions between males were highly ritualized, involving little or no actual contact between participating males. And yet one of the "combatants" generally left the territory after one or two clashes with his opponent.

The game-theoretic approach to animal conflicts (Maynard Smith and Parker, 1976) has produced three major hypotheses on the means by which animals resolve disputes. (1) The arbitrary rule hypothesis states that residence (or nonresidence) is used as an arbitrary basis for determining the winner in territorial species. This hypothesis generates the prediction that residents will always win (or always lose), a prediction said to be met in at least one insect (Davies, 1978) but clearly not in $H$. comstocki in which takeovers occurred from time to time.

(2) The payoff asymmetry hypothesis states that differences in the value the two combatants assign to ownership of the territory determines which will win. The individual with the greater amount to lose by not holding the site will be more strongly motivated to maintain or acquire the territory. Because residents have generally invested more in acquiring knowledge about their territory, the loss of the site should usually be especially damaging to their reproductive chances. The payoff asymmetry hypothesis therefore predicts that residents will usually win conflicts with intruders. In $\mathrm{H}$. comstocki, however, when the resident was clearly smaller than the intruder, it lost 15 of 19 encounters.

(3) The resource-holding power asymmetry hypothesis argues that differences in the intrinsic fighting ability of the two combat- 
ants will determine winners and losers. If males differ in strength, age, size, physiological condition and so on, the stronger, more experienced, larger, better conditioned contestant should win. Many studies have demonstrated that these variables do influence the outcome of territorial struggles in insects (reviewed in Thornhill and Alcock, 1983). In particular, large males often enjoy a fighting or competitive advantage whether they are defending females directly (e.g. Crespi, 1986), resources attractive to females (e.g. Sigurjónsdóttir and Parker, 1981; Otronen, 1984; Thornhill, 1984; Hoffmann, 1987) or lek territories (e.g. Alcock, 1981; O'Neill, 1983; Shelly, 1987). The stratiomyid $H$. comstocki falls into this latter group, since the larger of two individuals is far more likely to gain or retain a territory in a clash with a smaller male.

\section{SUMMARY}

Males of the stratiomyid fly Hermetia comstocki compete for possession of entire agave plants with large males enjoying a great advantage in the ritualized aerial contests for control of perch territories. Flying males are sometimes attacked and killed by Efferia robberflies. Nevertheless, territoriality has reproductive benefits in that receptive females fly to defended agaves and mate with territory owners. Females appear more likely to visit those sites that are occupied most regularly by territorial males. The mating system appears to be an example of lek or male dominance polygyny centered at landmarks that serve as rendezvous sites for receptive females and males.

\section{ACKNOWLEDGEMENTS}

This work was sponsored by NSF grant BNS 8620352 and facilitated by Dr. Wade Sherbrooke, director the Southwestern Research Station of the American Museum of Natural History. Stephen L. Buchmann helped in identifying the fly. David Spadafore ably assisted in the field work.

\section{Literature Cited}

Alcock, $\mathbf{J}$.

1981. Lek territoriality in a tarantula hawk wasp Hemipepsis ustulata (Hymenoptera: Pompilidae). Behav. Ecol. Sociobiol. 8: 309-317.

1983. Consistency in the relative attractiveness of a set of landmark territorial 
sites to two generations of male tarantula hawk wasps (Hymenoptera: Pompilidae). Anim. Behav. 31: 74-80.

1987. Leks and hilltopping in insects. J. Nat. Hist. 21: 319-328.

1990. The mating system of Mydas ventralis (Diptera: Mydidae). Psyche 96: 167-176.

COLE, F. R.

1963. The Flies of Western North America. Berkeley, University of California Press.

Crespi, B. J.

1986. Size assessment and alternative fighting tactics of Elaphrothrips tuberculatus (Insecta: Thysanoptera). Anim. Behav. 34: 1324-1335.

Davies, N. B.

1978. Territorial defence in the speckled wood butterfly (Pararge aegeria): the resident always wins. Anim. Behav. 26: 138-147.

EMLen, S. T. AND L. W. ORing

1977. Ecology, sexual selection and the evolution of mating systems. Science 197: 215-223.

НІтснСОск, В. Е.

1976. Studies on life-cycles of 2 species of soldier flies (Diptera, Stratiomyidae) which affect sugarcane in Queensland. Bull. Ent. Res. 65: 573-578.

Hoffmann, A. A.

1987. A laboratory study of male territoriality in the sibling species Drosophila melanogaster and D. simulans. Anim. Behav. 35: 807-818.

JAMES, M. T.

1935. The genus Hermetia in the United States (Diptera, Stratiomyidae). Bull. Brooklyn Ent. Soc. 30: 165-170.

LEDERHOUSE, R. C.

1982. Territorial defense and lek behavior of the black swallowtail butterfly, Papilio polyxenes. Behav. Ecol. Sociobiol. 10: 109-118.

Maynard Smith, J. and G. A. Parker

1976. The logic of asymmetric contests. Anim. Behav. 24: 159-175.

O'NeILL, K. M.

1983. Territoriality, body size, and spacing in males of the bee wolf Philanthus basilaris (Hymenoptera; Sphecidae). Behaviour 86: 295-321.

OTRONEN, M.

1990. Mating behavior and sperm competition in the fly, Dryomyza anilis. Behav. Ecol. Sociobiol. 26: 349-356.

SHELLY, T. E.

1987. Lek behaviour of a Hawaiian Drosophila: male spacing, aggression and female visitation. Anim. Behav. 35: 1394-1404.

Sigurjonsdottir, H. and G. A. Parker

1981. Dung fly struggles: evidence for assessment strategy. Behav. Ecol. Sociobiol. 8: 219-230.

THORNHILL, R.

1984. Fighting and assessment in Harpobittacus scorpionflies. Evolution 38: 204-214. 
Thornhill, R. AND J. AlCOCK

1983. The Evolution of Insect Mating Systems. Cambridge, Harvard University Press.

ToFt, C. A.

1989. Population structure and mating system of a desert bee fly (Lordotus pulchrissimus; Diptera: Bombyliidae). 1. Male demography and interactions. Oikos 54: 345-358.

WALDBAuer, G. P.

1984. A warningly colored fly, Stratiomys badius Walker (Diptera, Stratiomyidae), uses its scutellar spines in defense. Proc. Ent. Soc. Wash. 86: 722-723. 

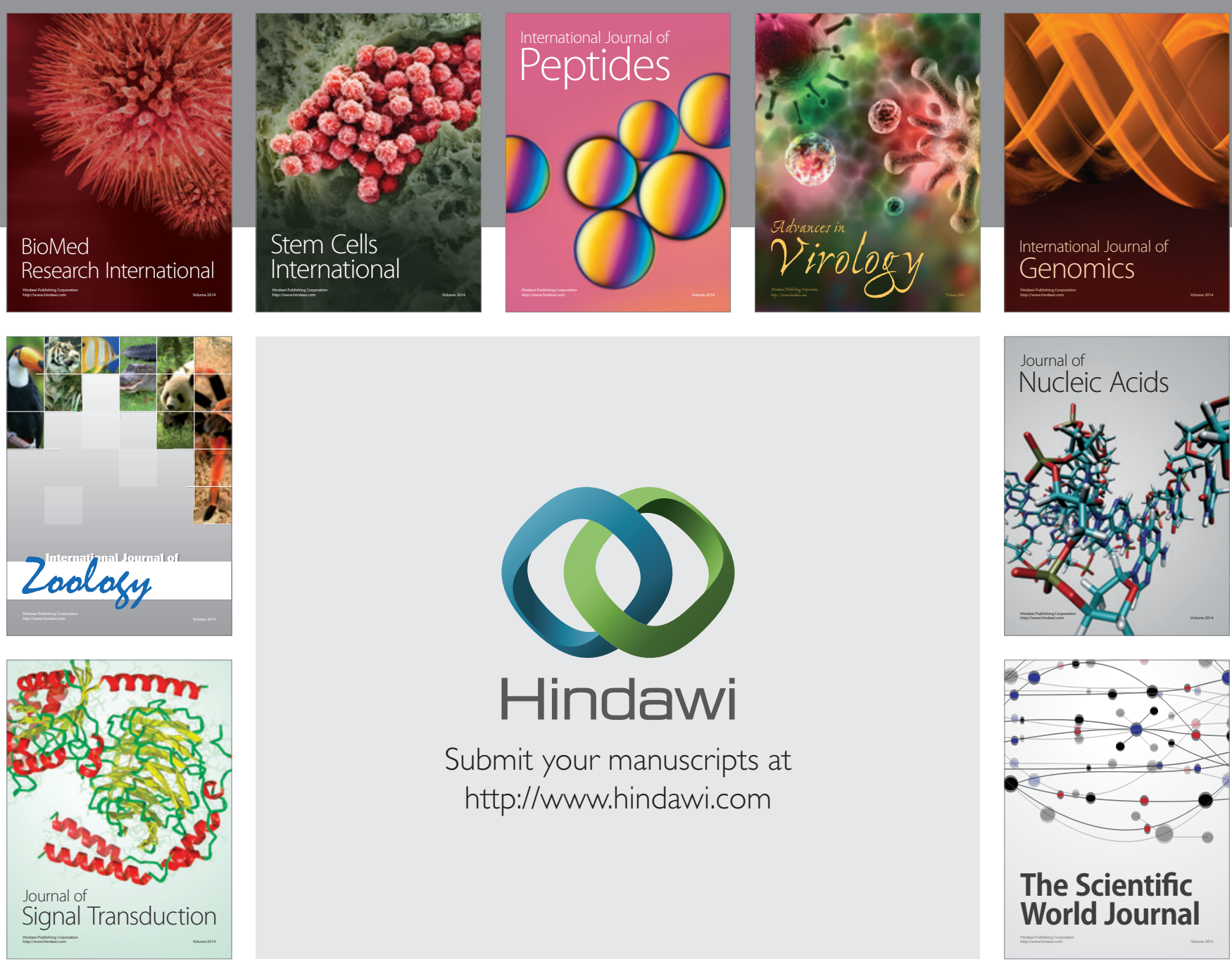

Submit your manuscripts at

http://www.hindawi.com
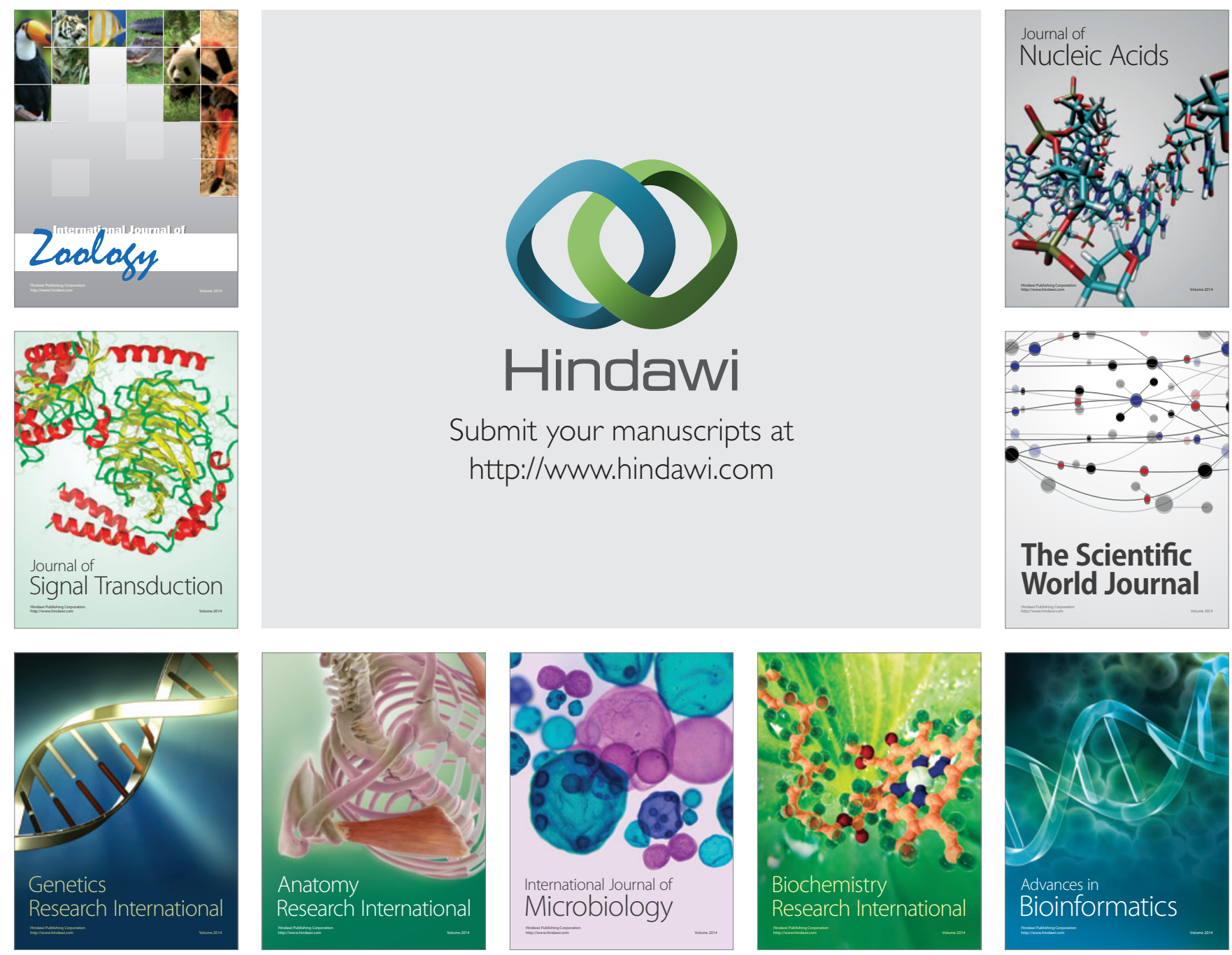

The Scientific World Journal
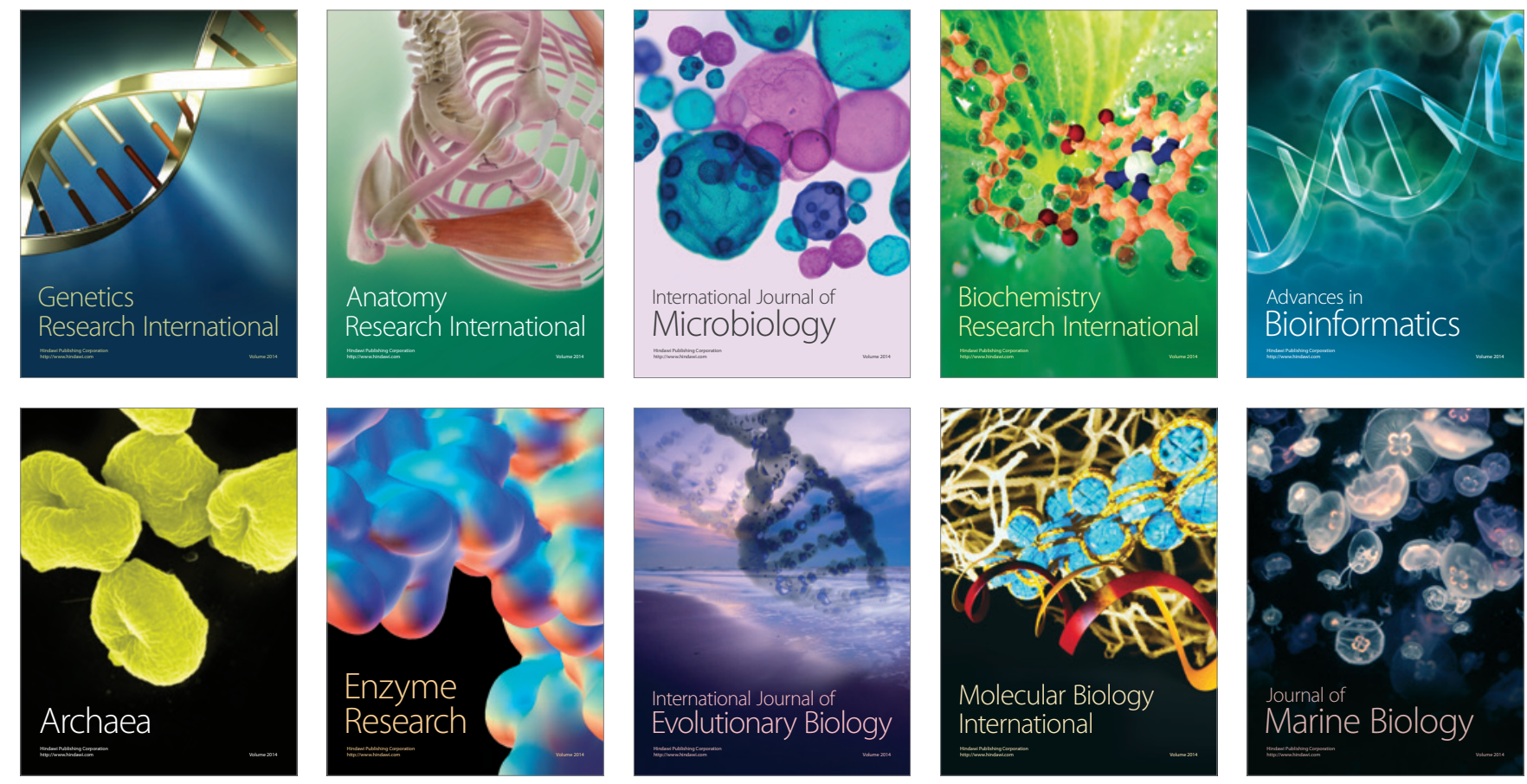